\title{
PARTICULARIDADE E ESTRANHEZA: EUCLIDES DA CUNHA
}

\author{
Vinícius Nicastro Honesko \\ Doutorando em Literatura - UFSC
}

\begin{abstract}
Resumo: Através da análise de algumas obras de Euclides da Cunha, o trabalho pretende armar uma rede de sentidos para o pensamento euclidiano. Partindo da idéia presente no termo regionalismo (regere limes), demonstra como numa primeira instância os textos de Euclides parecem estreitamente instruídos por uma lógica disjuntiva, a partir da qual se movimenta a escrita do autor. Nesta série de contrapontos, no entanto, verifica como esta pretensa rigidez da lógica de Euclides treme e se enfraquece por uma série de relatos contraditórios e aporéticos. A partir deste ponto, a proposta que vem à tona é que mais do que de caracterizações de instâncias limites e antagônicas, claramente representadas na dicotômica apresentação do sertão e do litoral, é de instâncias limiares, confins (limen), que o texto de Euclides trata. O jogo opositivoregressivo no qual parece se perder é exposto como marca de um estupor da razão, que impele Euclides às suas caracterizações contraditórias, nas quais, pode ser visto seu titubear - enquanto homem imerso em seu tempo (o engenheiro e positivista Euclides) e desconfiado de suas próprias apostas (o escritor Euclides).
\end{abstract}

Palavras-chave: Euclides da Cunha; Regionalismo; Confins; Estupor da Razão.

Résumé: À travers de 1'analyse de quelques textes de Euclides da Cunha, le travail prétend nouer une réseau de sens à la pensée euclidiènne. À partir de l'idée présente dans le terme régionalisme (regere limes), il démontre comme dans une première instance les textes de Euclides parâitent étroitement éclairés par une logique disjonctive, selon laquelle l'écriture de l'auteur se déplace. Dans cette série de contrepoint, pourtant, il vérifie comme cette soi-disant rigidité de la logique de Euclides tremble et s'affaibli par une série de récits contradictoires et aporétiques. À partir de ce point, la proposition qui aparaît est que plutôt que de caractérisations d'instances limites et antagoniques, celles-là qui sont clairemet montrés dans la présentation dichotomique du sertão et du littoral, ce sont des instances seuils, confins (limen), que s'agit dans le texte de Euclides. Le jeu oppositif-régressif dans lequel il semble d'être perdu est exposé comme marque d'un stupeur de la raison, ce qui pousse Euclides dans ses caracterisation contradictoires, dans lequelles est possible régarder sa hésitation - em tand que homme immergé dans son temps (l'ingénieur e positiviste Euclides) et méfiant de ses propres enjeux (l'écrivain Euclides).

Mots-clés: Euclides da Cunha; Régionalisme; Confins; Stupeur de la Raison. 
Regionalismo. Bom termo para se iniciar um texto sobre Euclides da Cunha. A relevância desta palavra pode ser atestada por uma, ainda que discreta e incidental, idéia genealógico-filológica: regionalismo, de regere limes, indica, grosso modo, a regência, a demarcação, a incisão dirigente de um poder supremo sobre um limite, sobre um território fronteiriço, último; este poder mesmo institui fronteira, marca um topos último, para além do qual sua regência está impedida de avançar. Eis o regionalismo. Necessário a esta idéia de regionalismo é a instauração de uma bipolaridade antagônica: aquilo que está dentro e aquilo que está fora; aquilo sobre o que o poder instaurador do limite ainda recai e o outro, o além-limite, sobre o qual é impossível àquele poder lançar seus tentáculos.

A narrativa de Euclides parece imbricar-se sempre neste espaço último que é representado, nestes termos, tanto pelo Sertão, quanto pela Amazônia. Pensando e retratando tais instâncias topográficas, Euclides procura apontar os problemas da conformação político-nacional brasileira; isto é, o engenheiro escritor que, como afirma Gilberto Freyre (in CUNHA, 1995, p. 18), "escreveu num estilo não só barroco esplendidamente barroco - como perigosamente próximo do precioso, do pedante, do bombástico, do oratório, do retórico, do gongórico, sem afundar-se em nenhum desses perigos: deixando-o apenas tocar por eles", parece deixar-se ir para além de sua postura cientificista ao se defrontar com certos obstáculos - para os quais, por vezes, aponta soluções peremptória e incisivamente positivistas, outras tantas deles desvia com artifícios narrativos.

Antes porém da verificação dos, por assim dizer, postulados euclidianos para os problemas político-nacionais, é importante ler sua postura diante dos espaços por ele colocados à margem da história. O sertão, representado na figura de Canudos (que coloca como índice que sumaria a fisiografia dos sertões do Norte) (CUNHA, 1995, p. 121), é um deserto; é um ponto onde a civilização pára - é um limite. Neste sentido, o sertão está isolado num além; uma região que se mostra limite - limes -, estaca demarcatória do poder regimental de territórios. Do mesmo modo, a Amazônia (com seu par simétrico: Canudos) é um lugar estrangeiro ao poder nacional; permanece ulterior, além do último enlace demarcatório. Tanto exterior é o estágio amazônico que Euclides logo declara:

A impressão dominante que tive, e talvez correspondente a uma verdade positiva, é esta: o homem ali, é ainda um intruso impertinente. Chegou sem ser esperado nem querido - quando a natureza ainda estava arrumando o seu mais vasto e luxuoso salão. E encontrou uma opulenta desordem... (CUNHA, 1995, p. 249)

Ao homem resta a hostilidade de um topos no qual se encontra na condição de integral estrangeiro. Além destas análises, Euclides faz uso da metáfora do estrangeiro em terra própria para marcar a condição do brasileiro que no território amazônico se encontra (bem como inverte as polaridades de sua lógica, para um homem abandonado por sua terra):

Naqueles lugares, o brasileiro salta: é estrangeiro: e está pisando terras brasileiras. Antolha-se-lhe um contra-senso pasmoso: À ficção de direito estabelecendo por vezes a extraterritorialidade, que é a pátria sem a terra, contrapõe-se uma outra, rudemente física: a terra 
sem a pátria. É o efeito maravilhoso de uma espécie de imigração telúrica. A terra abandona o homem. Vai em busca de outras latitudes. E o Amazonas, nesse construir o seu verdadeiro delta em zonas tão remotas do outro hemisfério, traduz, de fato, a viagem incógnita de um território em marcha, mudando-se pelos tempos adiante, sem parar um segundo, e tornando cada vez menores, num desgastamento ininterrupto, as largas superfícies que atravessa. (ibid., p. 254)

Também em Os Sertões, quando da contraposição entre as formações culturais e históricas do norte e do sul do Brasil, Euclides aponta as características que agravavam a colonização do sertão. Este é inabordável, e confere uma paralisação da evolução dos tempos - que, frise-se, era um dado incontestável na postura positivista de Euclides -, de modo a moldar um espaço anacrônico, an-histórico, à margem da história.

A dicotomia resultante da operação inclusivo-exclusiva de Euclides parece ser taxativa (a civilização e a barbárie, o sertão e o litoral; além disso, há o espaço da terra amazônica que se esvai de sob os pés dos patrícios para a dimensão da aquém(além)história, que se opõe ao espaço civilizado): "Estamos condenados à civilização. Ou progredimos, ou desaparecemos. A afirmativa é segura." (CUNHA, 1995, p. 149-150) Ou seja, a princípio a operação lógica do pensamento de Euclides parece ser claramente de tipo binária, marcada pela noção de um ou disjuntivo. A contraposição marcada e estanque é signo proeminente e constante dos escritos de Euclides, o que deixa transparecer sua vinculação irrestrita às doutrinas científicas da época, principalmente aquelas de cunho raciais e evolucionistas. (CAPELA, 1. sem. 2004, p. 116)

O tempo euclidiano é justamente aquele retilíneo e homogêneo, que parte de uma pré-história imaginável, porém indescritível, e que percorre seu caminho rumo a um futuro completo, no qual a imagem e descrição fundem-se num amálgama salvífico do projeto evolucionista progressista (o fim da história, o tempo da completude humana, o termo absoluto e universal). Daí as preconizações de um colapso à barbárie; o único caminho, o caminho da verdade humana só pode ser o da civilização, do progresso caso contrário só resta a desaparição, a extinção.

A incisiva divisão opositiva de Euclides é ainda mais proeminente nas suas descrições das disparidades regionais do Brasil. O interior é sempre um ponto obscuro e isolado do litoral. Não só isso: a vastidão do território formava ilhas interioranas que se viam distantes e desconectadas não apenas em relação ao litoral, mas também uma em face da outra. A vastidão das terras brasileiras seria marcada pela imprecisão dos limites, esta agregada à indeterminação de uma raça única, de uma base orgânica nacional. Quando retrata a formação territorial e começa a expor como esta já estava praticamente completa no começo do século XIX, Euclides diz:

$\mathrm{O}$ grande trato de terras retratava aproximadamente a sua configuração atual, indefinida. Firmada a leste e ao sul pela desmedida faixa de uma costa maciça, pelo poente e norte ela derivava em traços indecisos, raro modelados pelas conformações geográficas e ambíguos no fugitivo de linhas imaginárias lançadas em regiões desconhecidas, ou cindindo as cabeceiras de rios problemáticos. (CUNHA, 1995, p. 361) 
Os empecilhos de uma formação tão díspar refletem-se no texto de Euclides, de modo que ele propõe o suprimento destas incongruências numa reconfiguração nacional única, determinada e que fixa limites próprios à impropriedade do território nacional.

O que há que se ressaltar, no entanto, é algo peculiar do pensamento de Euclides, isto que, veremos, será o nó górgio que o prende numa constante encruzilhada aporética. Em Contrastes e Confrontos, no ensaio Plano de uma Cruzada, o autor deixa transparecer a sua visão daquilo que para ele é o verdadeiro Brasil: justamente o sertão, o interior, o gigantesco espaço abandonado dos interiores insulares. Mas como para um autor que se deixa apresentar por cientista e progressista, que pretende a completude humana na civilização que desvela a cegueira da barbárie, aquilo que para ele é a própria barbárie, o retrato do atraso civilizatório, pode ser o que há de mais verdadeiro para a nação?

De fato, Euclides não diz ser o litoral o possível redentor e o elemento que irá agregar e integrar a nação, firmando-a na sua única e capsular base física. Não. Euclides não se deixa levar pela imagem daquilo que chama civilização de empréstimo.

O verdadeiro Brasil nos aterra; trocamo-lo de bom grado pela civilização mirrada que nos acotovela na Rua do Ouvidor; sabemos dos sertões pouco mais além da sua etimologia rebarbativa, desertus; e, a exemplo dos cartógrafos medievos, ao idealizarem a África portentosa, podíamos escrever em alguns trechos dos nossos mapas a nossa ignorância e o no nosso espanto: hic habent leones... (CUNHA, 1995 , p. 158)

A civilização brasileira que se acotovela no litoral não é a verdadeira, mas é apenas um empréstimo do Velho Mundo, que não conhece e nem sequer é capaz de se conhecer na sua base sólida, o sertão (o espaço interiorano cujos habitantes são os brasileiros de fato: o sertanejo). Entretanto, o que acontece com o fado da nação? Isto é, como é que a civilização será possível se é justamente em seu oposto - a barbárie sertaneja - que Euclides encontra o Brasil possível, a verdadeira unidade nacional?

Raúl Antelo lê no texto de Os Sertões, com algumas referências às idéias de Jorge Coli, um ponto crucial a partir do qual as vanguardas iriam tomar forma. De acordo com Antelo, o estilo hiperestético de fins do século XIX e do início do século XX é uma trama que tenta capturar as mais bárbaras sensações numa rede discursiva complexa:

Em resposta a esses desejos de emoções fortes, dos Poèmes Barbares (1862) de Leconte de Lisle, à Sagração da Primavera (1913) de Stravinsky, os artistas procuraram emoções violentas, primitivas, "bárbaras", vazada na mais sofisticada das linguagens, em que erotismo e crueldade se mesclavam, em nuanças preciosas de cores, matérias, sensações. Os sertões é epopéia nascida nesses tempos de refinamentos perversos, em que a barbárie é moda. (ANTELO, 1. sem. 2004, p. 13)

Admitida a complexidade na qual adentra Euclides, é importante perceber como aquelas primeiras cisões bipartidas (sertão/litoral; civilização/barbárie etc), tão presentes em alguns textos, começam a adquirir uma feição mais complexa, em cujo centro não se encontra uma questão de limite (limes), mas mais especificamente um problema de 
confim (limen), isto é, de um entre-lugar, de uma instância não definitiva e demarcatória, mas um limiar que está no cruzamento de duas lógicas.

Todo o discurso cientificista de Euclides não chega ao ponto em que o autor aparentemente pretendia levá-lo, isto é, à exposição sem reservas de que a lógica do ou disjuntivo deveria imperar: a civilização ou o desaparecimento. Na verdade, o autor se espanta - se estupora - diante do lado obscuro, negativo do pensamento positivista. Aquilo que deveria desaparecer - o inculto sertanejo, o homem miscigenado, fraco - e que aparece num parêntesis irritante de Os Sertões, é descrito logo em seguida como o forte, o contraponto tenaz aos neurastênicos litorâneos.

Assim, no parêntese em que descreve os mestiços o faz nestes termos:

A mistura de raças mui diversas é, na maioria dos casos, prejudicial. Ante as conclusões do evolucionismo, ainda quando reaja sobre o produto o influxo de uma raça superior, despontam vivívssimos estigmas da inferior. A mestiçagem extremada é um retrocesso. $\mathrm{O}$ indo-europeu, o negro e o brasílio-guarani ou o tapuia, exprimem estádios evolutivos que se fronteiam, e o cruzamento, sobre obliterar as qualidades preeminentes do primeiro, é um estimulante à revivescência dos atributos primitivos dos últimos. De sorte que o mestiço - traço de união entre as raças, breve existência individual em que se comprimem esforços seculares - é, quase sempre, um desequilibrado. (CUNHA, 1995, p. 176)

No tópico seguinte, Euclides traz uma série de explicações para a posição do sertanejo como a parte fraca da miscigenação. A princípio as raças fortes naturalmente cooptariam as fracas pela civilização. No entanto, a narrativa toma um rumo diferente, e os "mestiços emergentes, variáveis, com todas as nuanças da cor, da forma e do caráter, sem feição definidas, sem vigor" e que seriam "os mutilados inevitáveis do conflito" (ibid., p. 178) tomam o posto dos fortes.

O sertanejo é, antes de tudo, um forte. Não tem o raquitismo exaustivo dos mestiços neurastênicos do litoral. A sua aparência, entretanto, ao primeiro lance de vista, revela o contrário. Falta-lhe a plástica impecável, o desempeno, a estrutura corretíssima das organizações atléticas. (ibid., p. 179)

Euclides claramente conjuga no sertanejo, aquele que outrora era um entrave à civilização, uma característica que lhe seria incompatível: a força. Nada mais evidente que a expressão: Hércules-Quasímodo.

O impossível torna-se possível no sertanejo. Ele, o fora da civilização é ao mesmo tempo o motor, a rocha-forte sobre a qual a civilização repousa. Diríamos, como Agamben, que a figura do sertanejo, pelo olhar do então civilizado, era apenas daquele matável e insacrificável. (AGAMBEN, 1999) Pura vida nua, despojada de qualquer direito, de qualquer passaporte para usufruir dos deleites civilizatórios. Porém, ao mesmo tempo - numa flagrante lógica excessiva -, o sertanejo transporta-se para o interior do sistema civilizado. Ele é o forte sobre o qual a unidade nacional - frise-se aí soberana-nacional - poderia se firmar.

A lógica do sertanejo é aquela da exceção: 
A exceção é uma espécie da exclusão. Ela é um caso singular, que é excluído da norma geral. Mas o que caracteriza propriamente a exceção é que aquilo que é excluído não está, por causa disto, absolutamente fora de relação com a norma; ao contrário, esta se mantém em relação com aquela na forma da suspensão. A norma se aplica à exceção desaplicando-se, retirando-se desta. (ibid., p. 25)

O estupor que toma conta de Euclídes, quando ele está diante de Canudos, ou ainda na Amazônia, é justamente o motor de sua escrita. O curto-circuito da lógica disjuntiva é incontornável. Para a resolução da progressão ou do desaparecimento Euclides não acha iluminação. Ele é ofuscado por esta própria luz - a razão, a iluminação - que o deveria iluminar e aquilo que escreve é o puro reflexo deste estupor. O trauma - reflexo desta incapacidade de resolução em pares díspares (ou uma coisa, ou outra) - refletido em Os Sertões e em À Margem da História expõe aquilo que para a estética de fins do século XVIII era a maravilha, o sublime. Ou seja, à maravilha precede uma ferida da razão (e aqui a filiação de Euclides às ciências o marca com a lisura da busca racional, portanto, o vislumbre de Canudos certamente lhe causou um espanto, lesionou sua razão), ferida esta que marca, deixa seu traço indelével, de modo a deixar a razão paralisada, como aqueles que viram Górgona ${ }^{1}$. Este entorpecimento carrega a razão de Euclides à vertigem, ao ofuscamento. Sua separação disjuntiva, a princípio tão pontual e própria, é obnubilada por aquele espaço imemorial que é Canudos (e também a Amazônia).

Tais espaços parecem marcar um precipício nos textos de Euclides. Como lembra Derrida, nas suas análises sobre o Timeu, existe algo no texto platônico que nos deixa perplexos: Khôra.

Khôra nos chega, e como o nome. E quando um nome vem, rapidamente diz mais que o nome, o outro do nome e o outro, simplesmente, do qual anuncia justamente a irrupção. Esse anúncio ainda não promete, não amaça mais. Ele não promete nem ameaça ninguém. Permanece estrangeiro à pessoa, nomeando somente a iminência, e ainda uma iminência estrangeira ao mito, ao tempo e à história de toda promessa e de todas as ameaças possíveis. (DERRIDA, 1995, p. 9)

Adiante continua:

Sobre ela [khôra] não se pode nem mesmo dizer que ela não é nem isto, nem aquilo, ou que é ao mesmo tempo isto e aquilo. Não basta lembrar que ela não nomeia nem isto, nem aquilo, ou que diz e isto e aquilo. O embaraço declarado por Timeu se manifesta de outra forma: algumas vezes a khôra não parece ser isso nem aquilo, outras simultaneamente isso e aquilo. (ibid., p. 10)

Do mesmo modo podemos dizer - alongando os termos - que Euclides abre um espaço tal como a khôra, que se reflete justamente no sertanejo. Este é, primeiramente, apenas aquilo que a civilização deve esmagar e não outra coisa; num segundo momento é o forte, o ponto de subsídio para a construção de uma nação brasileira.

Ora, essas idas e vindas do pensamento de Euclides denotam o seu titubear e confirmam sua estupefação. Ele é vítima da própria ânsia por desvelamento e descrição 
dos obscuros pontos que, segundo ele, estariam além do limes, fora dos limites, fora da região, além do poder nacional. Assim, diríamos que aquilo que se mostrava como obstáculo (limite, fim) é muito mais, no embaralhamento euclidiano, um limen - um entre-lugar, uma instância penúltima, indecidível. A khôra euclidiana é seu confrontarse com um inconfrontável; é o encontro com seu outro, com o outro de sua razão; é o confim da razão, seu limiar.

Como suscita Susana Scramim (1. sem. 2004, p. 99), Euclides pode ser visto do mesmo modo que as designações dos poetas arcaicos - como um Vates, "o possesso, o inspirado por Deus, em transe". Tal transe, ou estupefação, é o que leva Euclides para o lugar limiar. É também ele que mancha e machuca a razão euclidiana, forçando a escrever no paradoxo. De acordo com Antelo - e aqui o limiar da escritura euclidiana é remetida às figuras da interpretação nacional constantes tanto em Os Sertões, como em Contrastes e Confrontos, ou ainda em À Margem da História -, a estrutura da ficção interpretativa da realidade nacional descrita por Euclides é aquela do enigma, não do mistério:

O enigma é uma verdade parcelada, um brilho que, somado a outro, permite armar ou enunciar um continuum plural e fragmentado. Já o mistério alude a um todo coberto, velado. No mistério a imagem do véu nos separa do objeto e nos remete, imediatamente, ao longínquo, quando o enigma, pelo contrário, nos fala de uma distância no interior da própria representação. (ANTELO, 2001, p. 43)

A nossa proposta inicial - de verificar os, por assim dizer, postulados euclidianos para os problemas político-nacionais - pode ser desenvolvida a partir desta idéia do enigma nos discursos nacionalistas de fins de século XIX. Dessa forma, como diz Antelo,

na emergência do nacionalismo oficial latino-americano, na segunda metade do século XIX, as ficções de interpretação nacional cumprem essa função, muitas vezes erigindo esse valor à condição de mito, esquivando ou mesmo recusando-se a tratá-lo enquanto enigma, o que faz com que apelem, conseqüentemente, a procedimentos narrativos que representam essa identidade, desconhecida ou alterna, mas em todo caso, camuflada, como profundamente anômala. Nesse sentido, a linha de demarcação imaginária, a fronteira, adquire função simbólica fundacional. Essas ficções, como diria Euclides da Cunha, traçam o limite da loucura, revelam a zona intermediária onde se confundem facínoras e heróis, normalidade e transgressão. (id.)

A luta por uma unificação nacional, o discurso da coesão de Euclides, é posta justamente no espaço do enigma e do limiar. Na verdade, a disposição antagônica de civilizados e bárbaros, de litoral (ainda que este seja o locus da civilização de empréstimo) e sertão - que, forçando-se, pode remeter àquela propensão estruturalista em diacronia e sincronia - não é capaz de saldar a dívida do encobrimento de um fundo vazio de significantes. O caráter obtuso do nacional é reiteradamente presente, ainda que tal presença expurgue toda a possibilidade serial daqueles pontos díspares (dicotômicos).

Alongando as análises de Agamben, propostas no seu ensaio sobre $O$ País dos Brinquedos, no qual o autor discorre sobre o problema do tempo e da história a partir 
das análises estruturalistas (AGAMBEN, 2004), ${ }^{2}$ podemos dizer que Canudos representa claramente a fratura dos eixos antagônicos. Ele é a exposição do tempo intermediário, limiar, caprichosamente heterogêneo à civilização e, por sua vez, possibilitador da própria civilização. Diríamos que jamais a proposta evolucionista do "ou progredimos, ou desaparecemos" teria um termo; jamais porque tal estado de cumprimento do tempo em estado puro, de fim da história, tanto pelo aniquilamento (isto é, o fim decretado por desaparição), como pelo concreção e alcance da maioridade civilizatória (o homem que se descobre dono de si), é apenas o sonho da supressão do resíduo obtuso do existente puro (nesse sentido, do prius absoluto), isto é, da pura vida imanente do homem (esta que não se encontra no além limes, mas no entre limens).

Ainda citando Agamben:

Neste sentido, tanto as sociedades quentes quanto as frias parecem perseguir - em direções opostas - um mesmo projeto, que se poderia definir (e foi definido) como de "abolição da história". Porém, embora - ao menos por ora - as primeiras tenham conseguido multiplicar ao máximo a incidência de significantes diacrônicos, e as segundas reduzi-la, por sua vez, ao mínimo, nenhuma sociedade conseguiu realizar integralmente este projeto e fundar uma sociedade totalmente desprovida de calendário, como o país dos brinquedos, o reino de Hades ou até mesmo, em um certo sentido, a sociedade divina: nas sociedades de história cumulativa, a linearidade do tempo é sempre refreada pela alternância e pela repetição calendárica do tempo festivo; nas sociedades de história estacionária, a circularidade é sempre interrompida pelo tempo profano. (ibid., p. 95-96)

A impossibilidade de uma unidade nacional, que suprimiria toda a divergência e heterogeneidade para a fundação de um reino do progresso eterno em Terra Brazilis, é aquilo que Euclides toca, mas muitas vezes parece não querer ver.

Talvez o ensaio Judas-Asvero - em À Margem da História - seja um marco interessantíssimo para verificarmos como a descrição de Euclides da construção daquilo que se assemelha a um alter ego (o fantoche de Judas construído para ser malhado) do seringueiro - lembremos que este é aquele sertanejo que se deslocou do sertão para o deserto da Amazônia para tornar-se escravo do trabalho - acaba por expor o drama paradoxal do autor. Quando Euclides narra a confecção do Judas pelos seringueiros após confiar a robustez e a força ao sertanejo - parece querer expulsar toda aquela parte frágil (Quasímodo) do seu Hércules-Quasímodo; isto é, expurgar o elemento implícito de fraqueza sem, no entanto, assumir tal fraqueza. É como se, desdobrando-se no seu outro, o Judas, o seringueiro sertanejo fosse capaz de romper o ciclo perene de sua dor (não é sem significação que se trate de uma data festiva, que instaura um novo período isto é, um limite para um novo começo). Jogado no rio ${ }^{3}$ o Judas-Asvero percorre seu caminho para um infinito, para um vazio de representação, no qual, desaparecendo (e a imagem de Euclides da Cunha (1995, p. 297) é fantástica: "E acompanhando a correnteza, que se retifica na última espira dos remansos - lá se vão, em filas, um a um, vagarosamente, processionalmente, rio abaixo, descendo...", principalmente no que tange às reticências, que denotam o infinito descer) faria desaparecer o espaço residual que separa o sertanejo da civilização - isto é, sua parte Quasímodo; aí sim, limpo e purificado da parcela de imagem que lhe degrada (que se foi com o Judas), o sertanejo daria o supedâneo completo para a unidade nacional. 
Ocorre que tal expurgo não é senão artifício discursivo. Impossível é para o sertanejo (e para a civilização, no seu revés) livrar-se de sua parte residual (obtusa e "dejetual" - excesso). Assim, podemos verificar que a lógica disjuntiva parece persistir no texto de Euclides, ainda que agora ela seja lançada para o interior do próprio elemento limiar - que neste caso é o sertanejo seringueiro. Por isso o assombro de Euclides. Ele não pode negar sua postura mas, ao mesmo tempo, já o fez, ainda que no seu fazer encontremos restos da operação da lógica positivista (tal como tentamos mostrar no ensaio Judas-Asvero).

Quando Euclides rompe a crosta do limite e se certifica de que lá não há um além (uma história perfeita, uma civilização perfeita, um tempo perfeito), mas tão somente vê que lá está um limiar (um espaço-entre, um con-fim, uma soleira em que sua razão não encontra mais solo sob seus pés - "naqueles lugares, o brasileiro salta: é estrangeiro - e está pisando em terras brasileiras"), ainda que tente se agarrar à lógica que lhe servia como guia para a vida, vê que não mais é esta a questão. Salta, vê-se arranhado, não pode tampar os lugares abertos sem a abnegação da solidez da razão. $O$ paradoxal - tão analisado e ressaltado nas obras de Euclides - não é um simples descaso do autor em relação ao que vê (Canudos, a Amazônia) e aquilo que sente (o engenheiro Euclides, o homem de letras e de ciências), mas é seu espanto diante dos buracos que este muro Euclides das ciências possui. Para lidar com sua suspeita em relação a si mesmo só resta ao engenheiro um caminho: a escritura.

\footnotetext{
${ }^{1}$ Interessante é a análise de I Sommersi e i Salvati, de Primo Levi, empreendida por Agamben em Quel che resta di Auschwitz (quando o filósofo italiano discorre sobre o testemunho). Primo Levi quando discursa sobre os muçulmanos - aqueles que já tinham ultrapassado qualquer perspectiva de vida nos campos - diz que eles são aqueles que viram a Górgona. Diante disso - e a partir das idéias de FrontisiDucroux -, Agamben relata que para os gregos a Górgona representava uma impossibilidade da visão, mas ao mesmo tempo aquilo que era impossível não ver. Voltando ao texto de Levi ele diz: "Mas agora, como nome do muçulmano, "quem viu a Górgona" não é uma designação simples. Se ver a Górgona significa ver a impossibilidade de ver, então a Górgona não nomeia algo que está ou advém no campo, uma coisa que o muçulmano teria visto e não o sobrevivente. Esta designa muito mais a impossibilidade de ver daquele que está no campo, de quem, no campo, "tocou o fundo", tornou-se não homem. $\mathrm{O}$ muçulmano não viu nem conheceu nada - a não ser a impossibilidade de conhecer e de ver. Por isso, testemunhar para o muçulmano, tentar completar a impossibilidade de ver não é uma tarefa fácil. Que no "fundo" do humano não haja nada além de uma impossibilidade de ver - esta é a Górgona, cuja visão transformou o homem em não-homem. Mas que exatamente esta não humana impossibilidade de ver seja aquilo que chama e interpela o humano, os apóstrofos dos quais o homem não pode se livrar - isto, e não outra coisa é o testemunho. A Górgona e aquele que a viu, o muçulmano e aquele que testemunha por ele, são um único olhar, uma só impossibilidade de ver." (AGAMBEN, 1998, p. 49, trad. minha)

${ }^{2}$ Depois de sintetizar a fórmula de Lévi-Strauss da correlação entre sincronia e diacronia (jogo e rito), que abole uma antiga distinção entre povos com história e povos sem história, e instaura a diferenciação a partir da noção de sociedades frias ou sociedades quentes, Agamben sugere (no rastro da idéia de LeviStrauss de que o rito e jogo cumprem papéis opostos, porém complementares na formação das sociedades: aquele estratifica este, enquanto este tenta fazer das estruturas daquele um evento) a coesão estrutural de rito e jogo. Isto é, o copertencimento originário das duas esferas na ordem da produção histórica: "Desta correlação estrutural entre rito e jogo, entre diacronia e sincronia, já podemos derivar conseqüências nada irrelevantes. Pois se as sociedades humanas se nos mostram sob esta luz, como um conjunto único percorrido por duas tendências opostas, a primeira delas destinada a transformar a diacronia em sincronia e a outra direcionada ao efeito oposto, aquilo que por fim resulta do jogo destas tendências, aquilo que o sistema - a sociedade humana - produz, é, de qualquer forma, um resíduo diferencial entre diacronia e sincronia, é história, isto é, tempo humano.” (p.91) A ordem dos termos é
} 
que define um tipo de sociedade, de modo que a diferenciação entre sociedades quentes (de história cumulativa) e sociedades frias (de história estacionária) seria não tanto qualitativa quanto quantitativa.

${ }^{3}$ Interessante aqui é trazer a análise de Antelo (2001, p. 31) em relação ao rio nas representações nacionalistas: "Na representação do espaço nacional, tanto o papagaio quanto o rio são elementos obtusos porque precisamente postulam o infinito da linguagem como suplemento dificilmente digerível. Nessa percepção obtusa, verdade e mistério, visível e legível, atração e desvio quebram a ilusão harmônica de toda a construção, configurando, como dirá Barthes, um significante sem significado, descontínuo e indiferente à história, a contrapelo de toda a prática majoritária de significação e definido como puro gasto, o excesso sem intercâmbio de uma significância local ou menor, que ainda não pertence à política atual embora já anuncie, pela sua própria desaparição, a política futura."

\section{REFERÊNCIAS}

AGAMBEN, Giorgio. Quel che resta di Auschwitz: L'archivio e il testimone (Homo sacer III). Torino: Bollati Boringhieri, 1998.

. Homo Sacer: O poder soberano e a vida nua. Belo Horizonte: UFMG, 1999.

. Infância e história: Destruição da experiência e origem da história. Belo Horizonte: UFMG, 2004.

ANTELO, Raúl. Transgressão e modernidade. Ponta Grossa: UEPG, 2001.

. Séries e sertão. Outra travessia: Revista de literatura. N. 2. Florianópolis: UFSC, 1. sem. 2004.

CAPELA, Carlos E. Schmidt. Esse ser tão estrangeiro. Outra travessia: Revista de literatura. N. 2. Florianópolis: UFSC, 1. sem. 2004.

CUNHA, Euclides da. À margem da história. In: Coutinho. V. I. Rio de Janeiro: Nova Aguilar, 1995. . Obra completa. Org. Afrânio

. Contrastes e confrontos. In: . Obra completa. Org. Afrânio Coutinho. V. I. Rio de Janeiro: Nova Aguilar, $19 \overline{95 .}$

Os sertões. In: . Obra completa. Org. Afrânio Coutinho. V. II. Rio de Janeiro: Nova Aguilar, 1995.

DERRIDA, Jacques. Khôra. Campinas: Papirus, 1995.

FREYRE, Gilberto. Euclides da Cunha, revelador da realidade brasileira. In: CUNHA, Euclides da. Obra completa. Org. Afrânio Coutinho. V. I. Rio de Janeiro: Nova Aguilar, 1995.

SCRAMIM, Susana. Literatura em transe: Arcaísmos: Literatura e Religião. Outra travessia: Revista de literatura. N. 2. Florianópolis: UFSC, 1. sem. 2004. 